\title{
PSEUDO-ANEURISMA ARTERIAL PÓS-TRANSPLANTE RENAL
}

\section{POSTTRANSPLANT RENAL ARTERY PSEUDOANEURYSM

\author{
Luís Felipe da Silva - TCBC- RJ ${ }^{1}$; Ana Cristina de Oliveira Marinho-ACBC - RJ ${ }^{2}$; \\ Renato Torres Gonçalves ${ }^{3}$; Fábio Bellizzi Ferreira ${ }^{4}$
}

\section{INTRODUÇÃO}

O transplante renal, uma das formas de tratamento da insuficiência renal crônica terminal, tem fundamental importância no prolongamento e melhora da qualidade de vida do paciente portador desta doença ${ }^{1}$. O avanço na técnica operatória e no controle imunossupressor para o transplante renal reduziu as taxas de complicações cirúrgicas, quanto à morbidade e mortalidade nos receptores. Nas séries iniciais as taxas de complicações vasculares alcançavam valores em torno de $30 \%$, atualmente são inferiores a $6 \%$. Porém, quando presentes, constituem um sério problema pela possibilidade de causar alterações funcionais e até perda do enxerto renal por sangramento ou hipertensão ${ }^{2}$. A trombose e o sangramento geralmente ocorrem precocemente no período pós-operatório, enquanto a estenose arterial e outras complicações vasculares podem surgir a qualquer momento após o transplante renal. O pseudo-aneurisma é uma complicação vascular rara, sendo o tratamento cirúrgico imperativo para evitar a ruptura arterial ${ }^{3}$.

Neste artigo discutiremos o diagnóstico e a conduta de um caso de pseudo-aneurisma arterial de boca anastômica após enxerto renal.

\section{RELATO DO CASO}

Paciente de 29 anos do sexo feminino, parda, natural do Rio de Janeiro, com insuficiência renal crônica em tratamento por hemodiálise há 16 anos, foi em 1986, submetida a seu primeiro transplante renal, sendo o rim esquerdo doado por sua mãe e realizado o explante do mesmo logo após, devido à rejeição aguda.

Novo transplante com doador cadáver realizado em 05/08/2003, por uma incisão paramediana pararetal interna esquerda e acesso retroperitoneal. As anastomoses realizadas foram: término lateral entre a veia e a artéria do órgão doado, e a veia e artéria ilíacas externas esquerda do receptor, utilizando-se fio de prolene 6(0) em chuleio simples, e na implantação do ureter utilizou-se a técnica de Gregoire. O tempo total cirúrgico foi de 3 horas e 30 minutos, sem intercorrência.

No segundo dia pós-operatório a paciente evoluiu com febre e redução do débito urinário, sendo levantada as hipóteses diagnósticas de rejeição aguda, infecção urinária ou intoxicação por drogas. Foram colhidas amostras de urina e sangue em 09/08/2003 e isolado Pseudomonas aeruginosa. Mantida em uso de cefepime conforme antibiograma durante 14 dias. Recebeu alta em 28/08/2003 após 25 dias de internação, em boas condições clínicas e em uso dos imunossupressores: Tacrolimus $10 \mathrm{mg}$ dia (FK 506), meticortem $40 \mathrm{mg}$ dia e micofenolato mofetil (MMF) 1,5 gr dia.

Reinternada em 04/09/2003 por apresentar febre, calafrios e diarréia. Realizado nova investigação clínica incluindo ecocardiograma, cultura de sangue e urina, tendo sido isolado Stafilococos warneri. Contudo não foi realizada antibioticoterapia devido a suspeita de contaminação nas culturas. Após dias dias recebeu alta por apresentar melhora clínica.

Retornou ao hospital em 19/10/2003 queixando-se de dor na articulação coxo-femoral esquerda, sem alterações importantes ao exame clínico, exceto por febre, discreta anemia e dificuldade na mobilização do membro inferior esquerdo. Ausência de dor e de massas palpáveis no abdômen. O exame vascular dos membros inferiores foi normal.

Foi submetida à TC de pelve e abdome que evidenciou massa peri-enxerto renal, compatível com pseudoaneurisma de boca anastomótica (Figura 1). Confirmada a hipótese diagnóstica após angiografia (Figura 2) e evidenciado crescimento de Pseudomonas aeruginosa, sensível a Imipenem, nas hemoculturas. Iniciado imediatamente antibioticoterapia com Imipenem, e realizado o explante do enxerto após ressecção do pseudoaneurisma (Figura 3), seguido de ligadura da artéria e veia ilíacas externas esquerda.

A paciente não apresentou sinal agudo de isquemia arterial de MIE que necessitasse de revascularização. A cultura da peça cirúrgica revelou presença de Pseudomona aeruginosa. Recebeu alta em 11/12/2003.

\footnotetext{
1. Chefe do Departamento de Cirurgia da Faculdade de Medicina da UFRJ; Professor Titular do Departamento de Cirurgia da Faculdade de Medicina da UFRJ; Cirurgião do Serviço de Cirurgia Vascular do HUCFF / UFRJ.

2. Cirurgiã do Serviço de Cirurgia Vascular do HUCFF; Mestre em Cirurgia Geral do Departamento de Cirurgia da Faculdade de Medicina da UFRJ.

3. Médico Nefrologista do Serviço de Nefrologia do HUCFF; Responsável pelo Setor de Transplante Renal do HUCFF.

4. Médico Residente de Cirurgia Vascular do Hospital Universitário Clementino Fraga Filho - UFRJ.

Recebido em 29/05/2005

Aceito para publicação em 01/07/2005

Conflito de interesses: Não há

Fonte de financiamento: Nenhum

Trabalho realizado no Hospital Universitário Clementino Fraga Filho, nos Serviços de Nefrologia, Cirurgia Vascular do Departamento de Cirurgia da Faculdade de Medicina da UFRJ.
} 


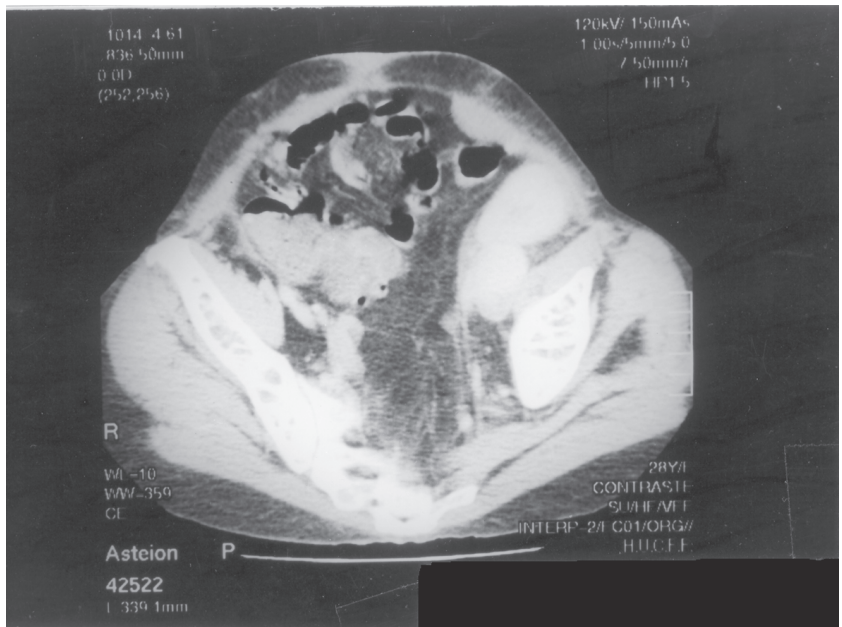

Figura 1 - Tomografia computadorizada de abdome demonstrando massa heterogênea em fossa ilíaca esquerda, próximo ao rim transplantado.

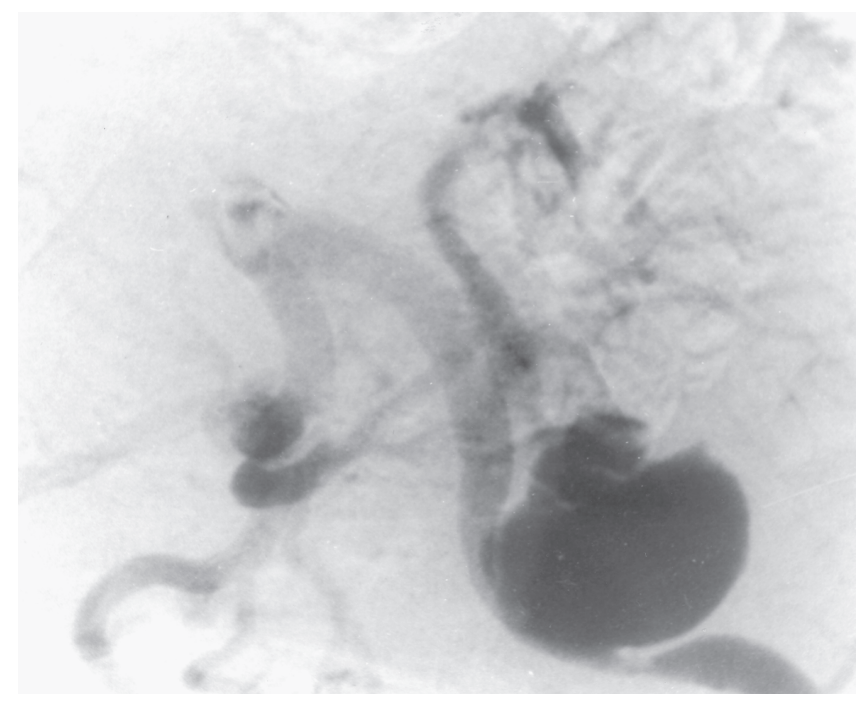

Figura 2 - Angiografia digital demonstrando pseudoaneurisma de boca anastomótica.

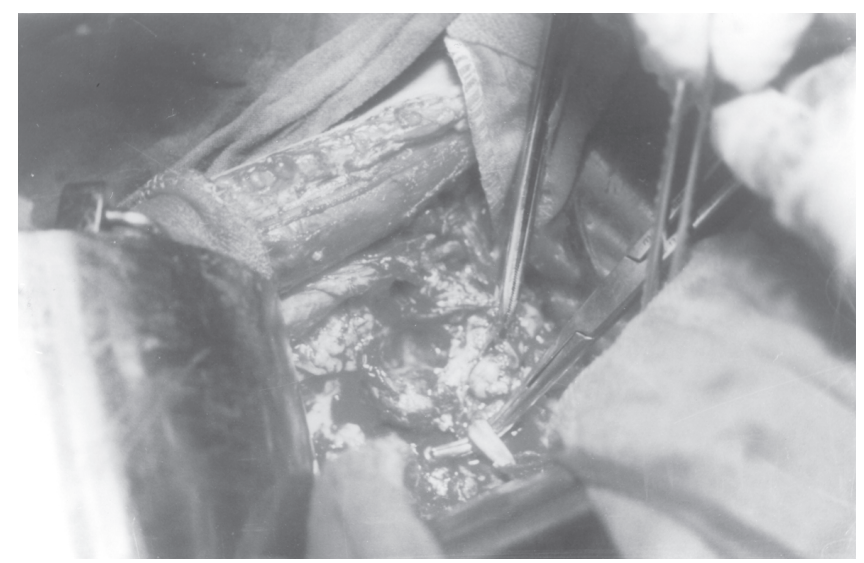

Figura 3 - Visão cirúrgica do pseudoaneurisma, com reparo da artéria ilíaca externa esquerda.

\section{DISCUSSÃO}

O aneurisma micótico foi descrito por Osler em 1885, para os aneurismas causados por embolia séptica conseqüen- te a uma endocardite bacteriana ${ }^{2}$. No entanto, ao longo do tempo este termo foi substituído por aneurisma infeccioso ou pseudo-aneurisma de boca anastomótica infectado, quando ocorre acometimento da linha de sutura e deiscência da mesma. Lacombe ${ }^{2}$ avaliou cinco casos de pseudo-aneurismas na área de sutura arterial do enxerto renal, relacionado à ocorrência de bacteremia, em datas variáveis, após a realização do transplante. Estes casos não apresentavam sinais de infecção na região cirúrgica adjacente. $\mathrm{Na}$ apresentação clínica desses pseudo-aneurismas é demonstrada a existência prévia de um quadro infeccioso, com migração bacteriana secundária por via hematogênica e sem infecção do campo operatório ${ }^{1}$.

Todos os pacientes transplantados são avaliados periodicamente quanto a possíveis complicações infecciosas, clínicas ou cirúrgicas. No momento do transplante é feito sistematicamente cultura do líquido de preservação do rim e após o transplante, cultura de urina periódica e hemoculturas em caso de bacteremia.

Nossa paciente necessitou de internação após o transplante por apresentar febre, decorrente de infecção urinária com conseqüente bacteremia.

A sintomatologia nestes casos é muito pobre, necessitando de investigação por métodos de imagem, ecodoppler e de angiografia para confirmar e visualizar a presença do pseudo-aneurisma. Esta paciente manifestou quadro de dor abdominal em fossa ilíaca esquerda (área do transplante) associada a febre, sendo avaliada por tomografia que demonstrou presença de massa junto ao rim transplantado. (Figura 1)

Após o diagnóstico do pseudo-aneurisma é imperativo a identificação do germe, e o estudo da sensibilidade a antibiótico para condução do tratamento medicamentoso. $\mathrm{O}$ germe isolado neste caso foi a Pseudomona aeruginosa multiresistente.

Os resultados do transplante renal podem ser seriamente afetados pelas complicações cirúrgicas vasculares, pondo em risco a circulação do membro inferior, assim como a vida do paciente. Em relação ao tratamento do pseudoaneurisma, além da antibioticoterapia, é necessária a reintervenção cirúrgica para realizar a explante do enxerto ${ }^{4,5}$ ou reconstrução e preservação do enxerto renal, conforme preconiza Lacombe ${ }^{2}$. Nesta paciente foi optado por ligadura da artéria e veia ilíacas externas e explante do enxerto.

Karakayah et $\mathrm{al}^{4}$, mostram em sua série, dois casos em que ocorreu a ruptura arterial e que foram tratados por ligadura e explante do enxerto, conforme conduta por nós utilizada. Emiroglu et $a l^{5}$, relatam em sua série, que somente ocorreram complicações vasculares nos pacientes em que foi adotada a técnica de anastomose término-terminal com a artéria ilíaca interna em relação à anastomose término-lateral com a artéria ilíaca externa, No entanto, o número de pacientes em que foi realizada a anastomose com a artéria ilíaca externa foi menor, $12,5 \%$ contra $80,2 \%$.

Embora a adoção da técnica de anastomose terminolateral com a artéria ilíaca externa seja preconizada em grande número de serviços ${ }^{4,5}$, o nosso adota de rotina a técnica de anastomose término-terminal com a artéria ilíaca interna, sen- 
do a anterior, reservada para os casos em que a artéria ilíaca interna é inadequada por doença arteriosclerótica. No presente caso, onde foi utilizada a anastomose término-lateral na artéria ilíaca externa esquerda, devido a sua ligadura após retirada do enxerto, haveria risco de comprometimento agudo do fluxo para o membro inferior ipsilateral. Entretanto não foi necessário a revascularização uma vez que ocorreu compensação clínica do membro.
É importante prevenir problemas técnicos em todos os estágios do processo de transplante, e assegurar um monitoramento cuidadoso no pós-operatório, incluindo avaliações clínicas periódicas e de imagem.

Enfim, o pseudo-aneurisma de boca anastomótica é uma complicação rara, porém grave, devendo ser rapidamente diagnosticado e prontamente corrigido por tratamento cirúrgico.

\begin{abstract}
Vascular complications after kidney transplantation have been described and pseudoaneurysms represent a well-recognized vascular complication. Although the incidence of pseudoaneurysm is low, it may potentially cause graft loss or may even be fatal for the patients if it is not diagnosed and treated quickly. The authors report a case of renal artery pseudoaneurysm diagnosed two months posttransplantation with cadaveric graft, the treatment and literature data (Rev. Col. Bras. Cir. 2006; 33(6): 413-415).
\end{abstract}

Keys words: Kidney transplantation; Aneurysm, false; Postoperative complications.

\section{REFERÊNCIAS}

1. Samhan M, Sinan T, al-Mousawi M. Vascular complications in renal recipients. Transplant Proc. 1999;31(8):3227-8.

2. Lacombe M. Les anévrismes mycotiques après transplantation rénale. Chirurgie. 1999;124(6):649-54.

3. Orlic P, Vukas D, Drescik I, Ivancic A, Blecic G, Budiselic B, Velcic G, Maricic A, Oguic R, Mozetic V, Valencic M, Sotosek S, Vukas D Jr. Vascular complications after 725 kidney transplantations during 3 decades. Transplant Proc. 2003;35(4):1381-4.

4. Karakayah H, Basarna O, Moray G, Emiroglu R, Haberal M. Major postoperative complications of renal transplantation: results from a single center in Turkey. Transplant Proc. 2003;35(7):2657-9.

5. Emiroglu R, Karakayali H, Sevmis S, Arslan G, Haberal M. Vascular complications in renal transplantation. Transplant Proc. 2001;33(5):2685-6.
Como citar este artigo:

Silva LF, Marinho ACO, Gonçalves RT, Ferreira FB. Pseudoaneurisma pós-transplante renal - relato de caso. Rev Col Bras Cir. [periódico na Internet] 2006 Nov-Dez;33(6). Disponível em URL: www.scielo.br/rcbc

Endereço para correspondência:

Luís Felipe da Silva

Serviço de Cirurgia Vascular - Hospital Universitário Clementino Fraga Filho/UFRJ

Av. Brigadeiro Trompowsky s $/$. $^{\circ}$

Ilha do Fundão

21941-590 - Rio de Janeiro- RJ

Tel.: (0xx21) 2562-2701

E-mail: felipe@hucff.ufrj.br 